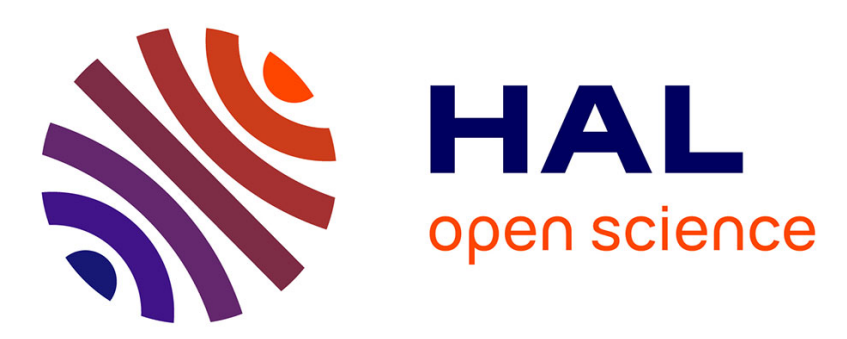

\title{
The microwave spectrum of isopropenyl acetate - An asymmetric molecule with two internal rotors
}

\author{
Ha Vinh Lam Nguyen, W. Stahl
}

\section{To cite this version:}

Ha Vinh Lam Nguyen, W. Stahl. The microwave spectrum of isopropenyl acetate - An asymmetric molecule with two internal rotors. Journal of Molecular Spectroscopy, 2010, 264 (2), pp.120-124. 10.1016/j.jms.2010.10.002 . hal-03183173

\section{HAL Id: hal-03183173 \\ https://hal.science/hal-03183173}

Submitted on 27 Mar 2021

HAL is a multi-disciplinary open access archive for the deposit and dissemination of scientific research documents, whether they are published or not. The documents may come from teaching and research institutions in France or abroad, or from public or private research centers.
L'archive ouverte pluridisciplinaire HAL, est destinée au dépôt et à la diffusion de documents scientifiques de niveau recherche, publiés ou non, émanant des établissements d'enseignement et de recherche français ou étrangers, des laboratoires publics ou privés. 


\title{
The Microwave Spectrum of Isopropenyl Acetate - an Asymmetric Molecule with two Internal Rotors
}

\author{
H.V.L. Nguyen and W. Stahl \\ Institute of Physical Chemistry, RWTH Aachen University, Landoltweg 2, D-52074 Aachen, \\ Germany
}

Corresponding author: Ha Vinh Lam Nguyen

Institute of Physical Chemistry

RWTH Aachen University

Landoltweg 2

D-52074 Aachen

Germany

Phone: +492418094759

Fax: +492418092365

Email: nguyen@pc.rwth-aachen.de

\begin{abstract}
The Fourier transform microwave spectrum of isopropenyl acetate $\left(\mathrm{CH}_{3}-\mathrm{COO}-\mathrm{C}\left(\mathrm{CH}_{3}\right)=\mathrm{CH}_{2}\right)$ has been measured under molecular beam conditions. The experimental data as well as quantum chemical calculations have shown that this molecule exists as only one conformer of $\mathrm{C}_{1}$ symmetry, in which the vinyl group is tilted by an angle of approximately $70^{\circ}$ against the plane containing the ester group. Due to internal rotation of the acetyl methyl group, we found large A-E splittings of all lines (from a few $\mathrm{MHz}$ up to $1 \mathrm{GHz}$ or more). We also were able to resolve the splitting due to the internal rotation of the second isopropenyl methyl group. The A species lines split into doublets and the E species lines into triplets. These splittings vary from $10 \mathrm{kHz}$ up to $1 \mathrm{MHz}$, much smaller than the splittings due to the acetyl methyl group. By analyzing the spectrum with the program Xiam, a torsional barriers of $135.3498(38) \mathrm{cm}^{-1}$ and $711.7(73) \mathrm{cm}^{-1}$ for the acetyl methyl group and the isopropenyl methyl group were observed, respectively. All lines in the spectrum were also fitted with the program Erham to a standard deviation of only $2.3 \mathrm{kHz}$.
\end{abstract}

Keywords: Microwave spectroscopy, Isopropenyl acetate, Internal rotation 


\section{Introduction}

From our studies on allyl acetate [1], $\mathrm{CH}_{3}-\mathrm{COO}-\mathrm{CH}_{2}-\mathrm{CH}=\mathrm{CH}_{2}$, we learned that the vinyl group was not located within the plane formed by the ester group, but tilted by an angle of $129^{\circ}$ against it. This induced us to investigate isopropenyl acetate, which is an isomer of allyl acetate. To the best of our knowledge no microwave studies have been carried out on this system before. We were interested to find out whether also in this case the isopropenyl group is tilted against the ester group.

Our interest in large amplitude motions also motivated us for this work. To our knowledge only very few acetate esters have been investigated. The first measured acetate ester was methyl acetate [2]. In this case, the barrier to internal rotation of the acetyl methyl group is $99.559(83) \mathrm{cm}^{-1}$. In our own studies on ethyl acetate [3] and allyl acetate [1], we observed a barrier of 101.606(23) $\mathrm{cm}^{-1}$ and $98.093(12) \mathrm{cm}^{-1}$, respectively. Therefore we expected also in the case of isopropenyl acetate a rather low hindering barrier on the order of $100 \mathrm{~cm}^{-1}$.

When Hirota studied the microwave spectrum of propene [4] he found a barrier to methyl rotation of $698.4(5) \mathrm{cm}^{-1}$. Since the situation in the isopropenyl group is similar, we expected also to be able to resolve the splittings due to the isopropenyl methyl group.

\section{Experimental}

Isopropenyl acetate was purchased from Merck Schuchardt OHG, Hohenbrunn, Germany. A gas mixture containing $1 \%$ isopropenyl acetate in a carrier gas at a total pressure of 100 to $200 \mathrm{kPa}$ was used throughout. In most cases helium was chosen because the rotational temperature of the molecular beam is not as low as with argon or neon and therefore also higher $\mathrm{J}$ levels can still be observed. All spectra were recorded using a molecular beam Fourier transform microwave (MBFTMW) spectrometer in the frequency range 4 to $26.5 \mathrm{GHz}[5,6]$. This spectrometer can be used in a high resolution mode as well as in a scan mode. In the scan mode a number of overlapping spectra are recorded in the high resolution mode. Since the direction of microwave propagation 
and gas pulse are co-axial [7], in the high resolution mode all lines are split into doublets due to the Doppler effect. The line width was in the range from 10 to $25 \mathrm{kHz}$, the line positions can be determined with an accuracy of $1 \mathrm{kHz}$ for strong lines and $5 \mathrm{kHz}$ for weaker lines.

A typical spectrum of the A and E species is shown in Fig. 1 and Fig. 2, respectively.

$<<$ Fig. 1 approximately here $>>$

$<<$ Fig. 2 approximately here $>>$

We found that some triplets, as the one in Fig. 2, show a narrow additional splitting on the order of $20 \mathrm{kHz}$. Under the influence of inhomogeneous magnetic fields these splittings vanished. We therefore attributed it to proton spin-spin or spin-rotation coupling as will be discussed below. 


\section{Spectral Analysis}

\section{Symmetry labels}

According to our ab initio calculations (see below) the point group of the isopropenyl acetate molecule is $\mathrm{C}_{1}$, i.e. it has no symmetry plane. There are two internal rotors, the acetyl methyl group with a rather low hindering barrier and the isopropenyl methyl group with a high barrier. The molecular symmetry group is isomorphic to the direct product group [8] $\mathrm{C}_{3}{ }^{(1)} \otimes \mathrm{C}_{3}{ }^{(2)}$. Both $\mathrm{C}_{3}$ symmetry groups involved have three one-dimensional symmetry species $\mathrm{A}, \mathrm{E}_{\mathrm{a}}, \mathrm{E}_{\mathrm{b}}$. We will label the rotorsional wave functions by $\mathrm{AA}, \mathrm{AE}=\mathrm{AE}_{\mathrm{a}}+\mathrm{AE}_{\mathrm{b}}, \mathrm{EA}=\mathrm{E}_{\mathrm{a}} \mathrm{A}+\mathrm{E}_{\mathrm{b}} \mathrm{A}, \mathrm{EE}=\mathrm{E}_{\mathrm{a}} \mathrm{E}_{\mathrm{a}}+\mathrm{E}_{\mathrm{b}} \mathrm{E}_{\mathrm{b}}$, and $E^{*}=E_{a} E_{b}+E_{b} E_{a}$. In a species $\Gamma_{1} \Gamma_{2}$ the acetyl methyl group will be represented by $\Gamma_{1}$ and the isopropenyl methyl group by $\Gamma_{2}$. Due to the low barrier of the acetyl methyl group all spectral lines show wide splittings into an A and an E component. The A component is split under the influence of the isopropenyl methyl group into a narrow AA, AE doublet, the $\mathrm{E}$ species splits into a narrow EA, EE, EE* triplet.

\section{Ab initio calculations}

In order to have reasonable rotational constants for spectral assignment we carried out a structure optimization at MP2/6-311++G** level using the Gaussian03 package [9]. This level of theory had been used for similar molecules before and usually yielded rotational constants which were quite close (approximately 1\%) to the experimental ones. A better agreement cannot be expected, because the calculated rotational constants refer to the equilibrium internuclear distances whereas the experimental constants are usually effective constants averaged by the zero point vibration. Besides the rotational constants also the angles $\angle(\mathrm{i}, \mathrm{g}), \mathrm{g}=a, b, c$ between the internal rotor axes and the inertial axes were calculated from the ab initio geometry, since they can directly be compared to our experimental data. The rotational constants and the angles are given in Tab. 1, the optimized geometry is shown in Fig. 3, the cartesian coordinates are available as supplementary material (Tab. S5).

$<<$ Fig. 3 approximately here $>>$ 
In this work we were only interested in the trans conformer of the ester. Cis esters are known to be much higher in energy and are therefore usually not observed under molecular beam conditions.

In contrast to our initial assumption the optimized structure had no symmetry plane and the isopropenyl group was tilted out of the plane of the ester group. Therefore we decided to calculate a potential curve where the dihedral angle $\varphi=\angle\left(\mathrm{C}_{5}, \mathrm{O}_{7}, \mathrm{C}_{8}, \mathrm{C}_{9}\right.$ ) (for atom numbers see

Fig. 3) was varied while all other geometry parameters were allowed to relax. The result is shown in Fig. 4. The curve has been parametrized by a Fourier expansion given in Tab. 2. The potential energy minima at $\varphi \approx \pm 70^{\circ}$ represent a pair of enantiomers. The same result is obtained by global structure optimization. Two $\mathrm{C}_{\mathrm{s}}$ geometries at $0^{\circ}$ and $\pm 180^{\circ}$ represent maxima in the potential curve and can be definitely excluded as stable conformers.

\section{$<$ Fig. 4 approximately here $>>$}

We also calculated the potential functions of the internal rotation of the isopropenyl methyl group and the acetyl methyl group in a similar manner. Again, the potential curves were parametrized by Fourier expansions. The Fourier coefficients are summarized in Tab. 2. Usually, the potential is given by the Fourier expansion

$$
\mathrm{V}(\alpha)=\frac{\mathrm{V}_{3}}{2}(1-\cos 3 \alpha)+\frac{\mathrm{V}_{6}}{2}(1-\cos 6 \alpha)+\ldots
$$

It should be noted that the $\mathrm{V}_{\mathrm{n}}$ potential $(\mathrm{n}=3,6, \ldots)$ is given by $\mathrm{V}_{\mathrm{n}}=2\left|\mathrm{a}_{\mathrm{n}}\right|$. For the isopropenyl methyl group we found a $V_{3}$ barrier of $656.2 \mathrm{~cm}^{-1}$ with a $V_{6}$ contribution below $2 \%$. The acetyl methyl group yielded a $\mathrm{V}_{3}$ barrier of $120.5 \mathrm{~cm}^{-1}$. Here a significant $\mathrm{V}_{6}$ term of $24.7 \mathrm{~cm}^{-1}$ was found, which is $20 \%$ of $\mathrm{V}_{3}$. As a consequence, the potential curve is a distorted cosine function with broadened minima and narrow maxima.

\section{Spectral assignment}

We started our experimental studies with a broadband scan recorded in the frequency range 9.3 to 14.5 GHz. Within this range, a total of 120 multiplets were found. All lines were remeasured in the high resolution mode. Almost all lines appeared as AA, AE doublets or as EA, EE, EE* triplets. In a first step we tried to fit the AA components separately with a rigid rotor program. It should be mentioned that $b$ - and $c$-type transitions were quite strong whereas $a$-type lines turned 
out to be very weak and could not be observed in the scan at all. After the AA components had been assigned, a complete spectrum with all torsional components was predicted using the Xiam [10] code. In a first approach we assumed the barrier of the acetyl methyl group to be approximately $100 \mathrm{~cm}^{-1}$ as found in methyl acetate [2], ethyl acetate [3], or allyl acetate [1], but no agreement with the observed spectrum was found. Then we successively increased the barrier up to $135 \mathrm{~cm}^{-1}$, where finally the observed and calculated spectra roughly matched. We fitted 50 transitions with 247 torsional components using the Xiam code. Since the A-E splitting caused by the acetyl methyl group is very large, whereas the splittings within the AA-AE doublets and the EA-EE-EE* triplets are rather small, we only fitted the absolute line positions of the AA and the EA lines. For the other species we fitted the AA-AE, EA-EE, and EA-EE* splittings referred to AA and EA, respectively. The narrow splittings, which contain the information of the high barrier could be fitted almost within the experimental uncertainty. On the other hand, the large splittings, determined by the low barrier, could be reproduced only within 10 to $350 \mathrm{kHz}$, which is on the same order of magnitude as the small splitting. Therefore, fitting all absolute positions of all lines would not allow to determine the high barrier. The resulting molecular parameters are given in Tab.1. A list of all fitted lines is available as supplementary material (Tab. S1 and S2). The standard deviation of the fit is $75.5 \mathrm{kHz}$. This is much larger than our experimental uncertainty which is estimated to be approximately $2 \mathrm{kHz}$. This discrepancy is due to the limitations of the Xiam code. In order to check for a correct assignment we fitted the same data set also with the Erham code [11] and found a standard deviation of $2.3 \mathrm{kHz}$ which is very close to experimental accuracy. The parameters fitted with Erham are also given in Tab. 1. A list of all fitted lines is given in the supplementary data (Tab. S3 and S4). The agreement between the rotational and centrifugal distortion constants, and also the angles between the internal rotor axes and the inertial axes obtained with Xiam and Erham is quite good. Unfortunately, the Erham code does not provide information on the potential barrier $V_{3}$ but only on more effective tunneling parameters. 


\section{Results and Discussion}

Our studies revealed some interesting aspects of the isopropenyl acetate molecule which are different from our initial ideas. In contrast to our assumption, but in agreement with our $a b$ initio calculations, isopropenyl acetate has no mirror plane. This has been confirmed by the observation of $c$-type AA species transitions. Moreover, more than $95 \%$ of all measured transitions could be assigned. Therefore it must be assumed, that only one conformer exists under molecular beam conditions. This is consistent with our attempts to find other conformers by ab initio calculations, where also only one conformer (as a pair of two enantiomers) was found.

The barrier to internal rotation of the acetyl methyl group was found to be approximately $135 \mathrm{~cm}^{-1}$, which is surprisingly high if compared to other acetates like methyl acetate [2], ethyl acetate [3], and allyl acetate [1], where the barrier is always on the order of $100 \mathrm{~cm}^{-1}$. However, it should be mentioned that in the case of vinyl acetate [12] a barrier of 155.1(1) $\mathrm{cm}^{-1}$ was found, which is still higher than the barrier found in isopropenyl acetate. Obviously, in both cases there is some delocalization of $\pi$-electrons extends from the vinyl double bond to the ester group, which increases the potential barrier. In the case of allyl acetate the vinyl group is not involved in delocalization and the barrier remains near $100 \mathrm{~cm}^{-1}$. However, we will continue our work on esters to study this feature in detail.

For the isopropenyl methyl group we found a barrier of $711.7(73) \mathrm{cm}^{-1}$. This is somewhat smaller than we expected at the beginning of our studies. However, it is in reasonable agreement with the barrier of 698.4(5) $\mathrm{cm}^{-1}$ reported by Hirota for propene [4], where the local environment of the methyl group is similar.

Finally, it should be mentioned that besides the splittings due to internal rotation additional very narrow splittings were observed. These splittings changed their appearance or they disappeared when the measurements were carried out in the presence of an inhomogeneous magnetic field ranging from one to five times the strength of the earth's magnetic field. Therefore we concluded that these extra splittings arise from proton spin-rotation and spin-spin coupling. It is surprising that the lines are influenced by those low external magnetic fields since it is often believed that in closed-shell molecules Zeeman effects due to the earth's magnetic field cannot be observed at all. 


\section{ACKNOWLEDGMENTS}

We thank the Center for Computing and Communication of the RWTH Aachen University for free computer time and the Land Nordrhein-Westfalen for funds. Furthermore, we thank R. Missong for her contributions within her bachelor thesis, J. Broda and C. Willems for the contributions within a student research project. Finally we would like to thank P. Groner for making his Erham code available to the spectroscopic community. 


\section{References}

[1] H.V.L. Nguyen, H. Mouhib, W. Stahl, and I. Kleiner, Mol. Phys. 108 (2010) 763.

[2] J. Sheridan, W. Bossert, and A. Bauder, J. Mol. Spectrosc. 80 (1980) 1.

[3] D. Jelisavac, D. Cortés Gómez, H.V.L. Nguyen, L.W. Sutikdja, W. Stahl, and I. Kleiner, J. Mol. Spectrosc. 257 (2009) 111.

[4] E. Hirota, J. Chem. Phys. 45, 1984 (1966).

[5] U. Andresen, H. Dreizler, J.-U. Grabow, and W. Stahl, Rev. Sci. Instrum. 61 (1990) 3694.

[6] J.-U. Grabow, W. Stahl, and H. Dreizler, Rev. Sci. Instrum. 67 (1996) 4072.

[7] J.-U. Grabow and W. Stahl, Z. Naturforsch. 45a (1990) 1043.

[8] H. Dreizler, Z. Naturforsch. 16a (1961) 1354.

[9] Gaussian 03, Revision D.02, M. J. Frisch, G. W. Trucks, H. B. Schlegel, G. E. Scuseria, M. A. Robb, J. R. Cheeseman, J. A. Montgomery, Jr., T. Vreven, K. N. Kudin, J. C. Burant, J. M. Millam, S. S. Iyengar, J. Tomasi, V. Barone, B. Mennucci, M. Cossi, G. Scalmani, N. Rega, G. A. Petersson, H. Nakatsuji, M. Hada, M. Ehara, K. Toyota, R. Fukuda, J. Hasegawa, M. Ishida, T. Nakajima, Y. Honda, O. Kitao, H. Nakai, M. Klene, X. Li, J. E. Knox, H. P. Hratchian, J. B. Cross, V. Bakken, C. Adamo, J. Jaramillo, R. Gomperts, R. E. Stratmann, O. Yazyev, A. J. Austin, R. Cammi, C. Pomelli, J. W. Ochterski, P. Y. Ayala, K. Morokuma, G. A. Voth, P. Salvador, J. J. Dannenberg, V. G. Zakrzewski, S. Dapprich, A. D. Daniels, M. C. Strain, O. Farkas, D. K. Malick, A. D. Rabuck, K. Raghavachari, J. B. Foresman, J. V. Ortiz, Q. Cui, A. G. Baboul, S. Clifford, J. Cioslowski, B. B. Stefanov, G. Liu, A. Liashenko, P. Piskorz, I. Komaromi, R. L. Martin, D. J. Fox, T. Keith, M. A. Al-Laham, C. Y. Peng, A. Nanayakkara, M. Challacombe, P. M. W. Gill, B. Johnson, W. Chen, M. W. Wong, C. Gonzalez, and J. A. Pople, Gaussian, Inc., Wallingford CT, 2004.

[10] H. Hartwig and H. Dreizler, Z. Naturforsch. 51a (1996) 923.

[11] P. Groner, J. Chem. Phys. 107 (1997) 4483.

[12] B. Velino, A. Maris, S. Melandri, W. Caminati, J. Mol. Spectrosc. 256 (2009) 228.

[13] P. Groner, S. Albert, E. Herbst, F. C. D. Lucia, F. J. Lovas, B. J. Drouin, and J. C. Pearson, ApJS 142 (2002) 145.

[14] P. Groner, Instructions for program ERHAM, available at http://www.ifpan.edu.pl/ kisiel/prospe.htm. 


\section{Tables}

Table 1: Molecular parameters of isopropenyl acetate obtained by a fit using programs Xiam, Erham, and ab initio calculations.

\begin{tabular}{|c|c|c|c|c|c|}
\hline parameter & unit & $\begin{array}{l}\text { Xiam } \\
\text { (obs) }\end{array}$ & Erham & $\begin{array}{c}a b \text { initio } \\
\text { (calc) }\end{array}$ & obs-calc \\
\hline \multicolumn{6}{|c|}{ Rotational and centrifugal distortion parameters } \\
\hline A & $\mathrm{GHz}$ & $4.992199(46)$ & $4.98543162(35)$ & 4.950 & 0.042 \\
\hline B & $\mathrm{GHz}$ & $1.804480(20)$ & $1.80464157(14)$ & 1.802 & 0.002 \\
\hline $\mathrm{C}$ & $\mathrm{GHz}$ & $1.651355(18)$ & $1.65156421(15)$ & 1.656 & -0.005 \\
\hline$\Delta_{\mathrm{J}}$ & $\mathrm{kHz}$ & $0.447(39)$ & $0.4440(17)$ & & \\
\hline$\Delta_{\mathrm{JK}}$ & $\mathrm{kHz}$ & $2.618(51)$ & $2.5143(29)$ & & \\
\hline$\Delta_{\mathrm{K}}$ & $\mathrm{kHz}$ & $-1.79(82)$ & $-1.633(37)$ & & \\
\hline$\delta_{\mathrm{J}}$ & $\mathrm{kHz}$ & $-0.0342(18)$ & $-0.03991(15)$ & & \\
\hline$\Delta_{\mathrm{K}}$ & $\mathrm{kHz}$ & $-1.79(82)$ & $-1.633(37)$ & & \\
\hline \multicolumn{6}{|c|}{ Torsional parameters of the acetyl methyl group } \\
\hline \multirow[t]{3}{*}{$\mathrm{V}_{3}$} & $\mathrm{GHz}$ & $4057.69(12)$ & & & \\
\hline & $\mathrm{kJ} / \mathrm{mol}$ & $1.619144(45)$ & & & \\
\hline & $\mathrm{cm}^{-1}$ & $135.3498(38)$ & & 120.5 & 14.9 \\
\hline $\mathrm{I}_{\gamma}$ & $\mathrm{u} \AA^{2}$ & 3.1586 (fixed) & $3.1380(60)$ & & \\
\hline$\angle(\mathrm{i}, \mathrm{a})$ & $\circ$ & $152.1715(67)$ & $152.641(14)$ & 150.4 & 1.8 \\
\hline$\angle(\mathrm{i}, \mathrm{b})$ & $\circ$ & $108.125(46)$ & $107.702(55)$ & 108.7 & -0.6 \\
\hline$\angle(\mathrm{i}, \mathrm{c})$ & $\circ$ & $110.369(43)$ & $110.156(33)$ & 112.1 & -1.7 \\
\hline $\mathrm{D}_{\mathrm{pi} 2 \mathrm{~J}}$ & $\mathrm{kHz}$ & $29.9(28)$ & & & \\
\hline $\mathrm{D}_{\mathrm{pi2}-}$ & $\mathrm{kHz}$ & $-1136.8(85)$ & & & \\
\hline$\rho$ & & & $0.01574(32)$ & & \\
\hline$\alpha$ & $\circ$ & & $160.58(12)$ & & \\
\hline$\beta$ & $\circ$ & & $50.47(32)$ & & \\
\hline$\epsilon_{10}$ & $\mathrm{MHz}$ & & $-5862(22)$ & & \\
\hline$\left[\mathrm{G}_{\mathrm{a}}\right]_{10}$ & $\mathrm{MHz}$ & & $-2.54(49)$ & & \\
\hline$\left[\mathrm{G}_{\mathrm{b}}\right]_{10}$ & $\mathrm{MHz}$ & & $-0.485(96)$ & & \\
\hline$[(\mathrm{B}+\mathrm{C}) / 2]_{10}$ & $\mathrm{kHz}$ & & $-14.63(15)$ & & \\
\hline$[\mathrm{A}-(\mathrm{B}+\mathrm{C}) / 2]_{10}$ & $\mathrm{kHz}$ & & $-447(23)$ & & \\
\hline$[(\mathrm{B}-\mathrm{C}) / 4]_{10}$ & $\mathrm{kHz}$ & & $-1.69(35)$ & & \\
\hline$\left[\Delta_{\mathrm{K}}\right]_{10}$ & $\mathrm{kHz}$ & & $-0.615(38)$ & & \\
\hline$\left[\delta_{\mathrm{J}}\right]_{10}$ & $\mathrm{kHz}$ & & $-0.001300(72)$ & & \\
\hline$\left[\delta_{K}\right]_{10}$ & $\mathrm{kHz}$ & & $-0.0137(63)$ & & \\
\hline
\end{tabular}


Table 1 (Cntd.)

\begin{tabular}{|c|c|c|c|c|c|}
\hline parameter & unit & $\begin{array}{l}\text { Xiam } \\
\text { (obs) }\end{array}$ & Erham & $\begin{array}{c}a b \text { initio } \\
(\text { calc })\end{array}$ & obs-calc \\
\hline \multicolumn{6}{|c|}{ Torsional parameters of the isopropenyl methyl group } \\
\hline \multirow[t]{3}{*}{$\mathrm{V}_{3}$} & $\mathrm{GHz}$ & $21337(217)$ & & & \\
\hline & $\mathrm{kJ} / \mathrm{mol}$ & $8.514(87)$ & & & \\
\hline & $\mathrm{cm}^{-1}$ & $711.7(73)$ & & 656.2 & 55.5 \\
\hline $\mathbf{I}_{\gamma}$ & $\mathrm{u} \AA^{2}$ & 3.1586 (fixed) & $3.582(62)$ & & \\
\hline$\angle(\mathrm{i}, \mathrm{a})$ & $\circ$ & $74.4(13)$ & $73.53(18)$ & 74.1 & 0.3 \\
\hline$\angle(\mathrm{i}, \mathrm{b})$ & $\circ$ & $24.8(22)$ & $26.51(15)$ & 27.4 & -2.6 \\
\hline$\angle(\mathrm{i}, \mathrm{c})$ & $\circ$ & $108.8(20)$ & $110.16(12)$ & 111.7 & -2.9 \\
\hline$\rho$ & \multicolumn{5}{|c|}{$0.01574(32)$} \\
\hline$\alpha$ & $\circ$ & \multicolumn{4}{|c|}{$160.58(12)$} \\
\hline$\beta$ & $\circ$ & \multicolumn{4}{|c|}{$50.47(32)$} \\
\hline$\epsilon_{01}$ & $\mathrm{MHz}$ & & $-3.118(77)$ & & \\
\hline \multicolumn{6}{|c|}{ al information } \\
\hline$\sigma$ & $\mathrm{kHz}$ & 75.5 & 2.3 & & \\
\hline $\mathrm{N}_{\text {tot }}$ & & 247 & 247 & & \\
\hline
\end{tabular}

${ }^{\text {a }}$ For the nomenclature of the parameters fitted with Erham, see [13].

${ }^{b}$ The meaning of $\left[G_{a}\right]_{10}$ and $\left[G_{b}\right]_{10}$ is $(1,0,-1,0,0,1)$ and $(1,0,-1,1,0,0)$, respectively, in the (IQ1,IQ2,MEG,KAP,JP,KP) notation used in the Erham program instructions available in [14]. 
Table 2: Parametrized potential functions calculated on $\mathrm{MP} 2 / 6-311++\mathrm{G} * *$ level. The total electronic energy is given by the Fourier expansion $\mathrm{E}=\mathrm{a}_{0}+\sum_{\mathrm{n} \geq 1} \mathrm{a}_{\mathrm{n}} \cos (\mathrm{n} \varphi)$.

\begin{tabular}{|c|c|c|c|}
\hline & Hartree & $\mathrm{kJ} / \mathrm{mol}$ & $\mathrm{cm}^{-1}$ \\
\hline \multicolumn{4}{|c|}{ rotation of the entire isopropenyl group } \\
\hline $\mathrm{a}_{0}$ & -344.9215097 & & \\
\hline$a_{1}$ & 0.0005181 & 1.360 & 113.7 \\
\hline$a_{2}$ & 0.0018659 & 4.899 & 409.5 \\
\hline$a_{3}$ & 0.0010433 & 2.739 & 229.0 \\
\hline $\mathrm{a}_{4}$ & 0.0003623 & 0.951 & 79.5 \\
\hline$a_{5}$ & -0.0000846 & -0.222 & -18.6 \\
\hline $\mathrm{a}_{6}$ & 0.0001161 & 0.305 & 25.5 \\
\hline a7 & 0.0000994 & 0.261 & 21.8 \\
\hline$a_{8}$ & 0.0000669 & 0.176 & 14.7 \\
\hline \multicolumn{4}{|c|}{ rotation of the acetyl methyl group } \\
\hline$a_{0}$ & -344.9235593 & & \\
\hline$a_{3}$ & -0.0002746 & -0.721 & -60.3 \\
\hline a6 & 0.0000562 & 0.148 & 12.3 \\
\hline$a_{12}$ & 0.0000069 & 0.018 & 1.5 \\
\hline \multicolumn{4}{|c|}{ rotation of the isopropenyl methyl group } \\
\hline $\mathrm{a}_{0}$ & -344.922297 & & \\
\hline$a_{3}$ & 0.001495 & 3.925 & 328.1 \\
\hline $\mathrm{a}_{6}$ & 0.000029 & 0.076 & 6.4 \\
\hline
\end{tabular}




\section{Figure Captions}

Fig. 1: A typical A species $4_{23} \leftarrow 4_{14}$ transition of isopropenyl acetate.

The experimental resolution was $0.8 \mathrm{kHz}$, the typical experimental line width $24 \mathrm{kHz}$ as indicated in the spectrum. The large splitting is due to the Doppler effect (indicated by brackets). For this spectrum 58 FIDs were co-added.

Fig. 2: A typical $E$ species $6_{15} \leftarrow 5_{23}$ transition of isopropenyl acetate.

Doppler splittings are indicated by wide brackets. The splitting indicated by small brackets is due to the spin-spin or spin-rotation-coupling. For this spectrum 120 FIDs were co- added.

Fig. 3: Geometry of the observed conformer of isopropenyl acetate.

Fig. 4: The potential curve of isopropenyl acetate obtained by rotating the isopropenyl group. The relative energy with respect to the lowest energy conformer is given. 
Fig. 1

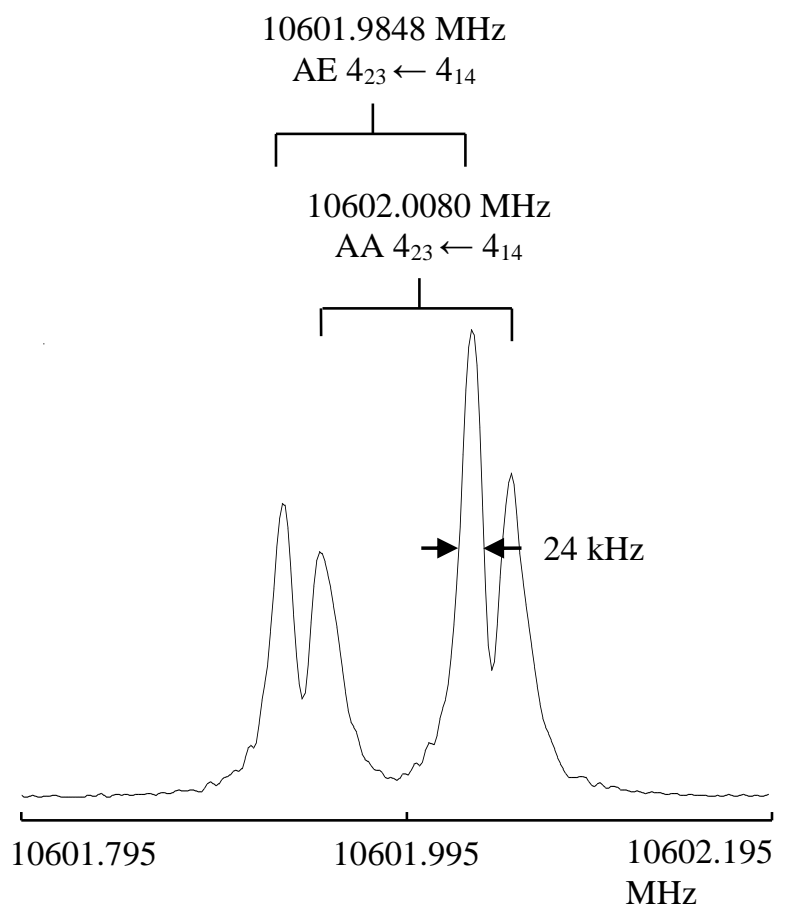


Fig. 2

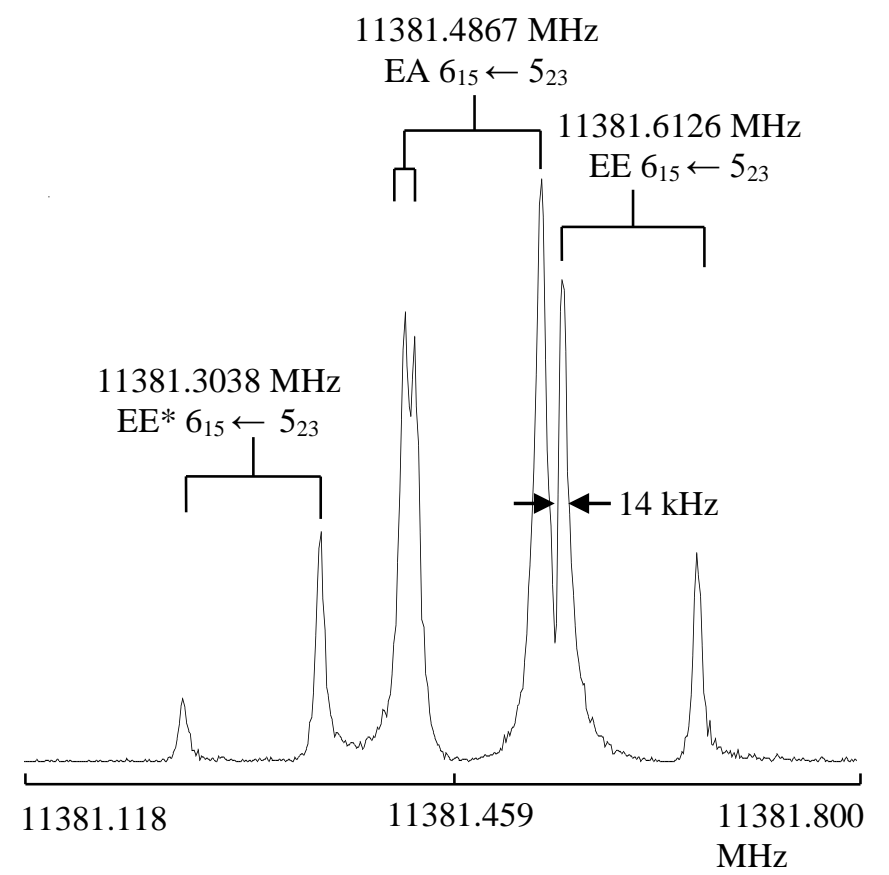


Fig. 3

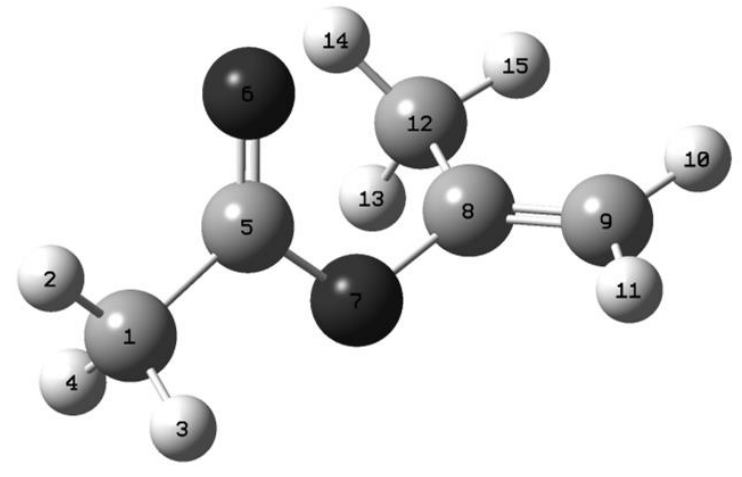


Fig. 4

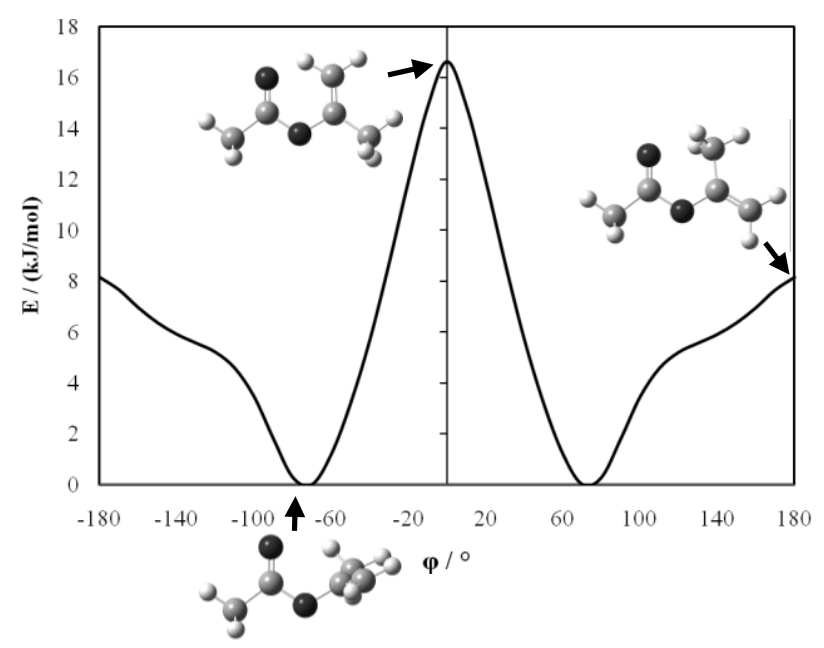

